\title{
O IRRECONCILIÁVEL NOS EDITAIS DO PNLD: EUROCENTRISMO, CIDADANIA E ENSINO DE HISTÓRIA
}

\author{
Taissa Cordeiro Bichara ${ }^{1}$
}

\begin{abstract}
Resumo: O estudo trata de análise sobre os sentidos atribuídos às categorias eurocentrismo, cidadania e ensino de história encaminhados pelos editais de convocação para o processo de inscrição e avaliação de obras didáticas e literárias publicados no Diário Oficial da União, pelo Ministério da Educação (MEC), submetidos ao Programa Nacional do Livro Didático (PNLD) e destinados aos Anos Finais do Ensino Fundamental, entre 1996 e 2018. Nestes, residem pressupostos que orientam o processo de avaliação do PNLD e relacionam-se com a produção das narrativas literárias didáticas. Neste sentido, argumenta-se que a busca pela formação de cidadania, associada ao ensino de história, situa determinados agentes históricos em posição de submissão ao universo identificado com a civilização ocidental - predominantemente branca e cristã - reforçando a matriz de referencial eurocêntrico nos livros didáticos de história.
\end{abstract}

Palavras-Chave: Livro Didático. Formação para cidadania. Ensino de História.

\section{THE IRRECONCILABLE IN PNLD (NATIONAL TEXTBOOK PROGRAM) DOCUMENTATION: EUROCENTRISM, CITIZENSHIP AND HISTORY TEACHHING}

\begin{abstract}
The study aims to analyze meanings attributed to the eurocentrism, citizenship and history teaching categories in the initial requirement documents for the process of registration and evaluation of didactic and literary books published in the Brazilian Official Gazette by the Ministry of Education (MEC), which are submitted both to the National Textbook Program (PNLD) and the Final Years of Elementary Education, between years 1996 and 2018. The documentation attends assumptions that guide the PNLD evaluation process besides being related to the didactic literary narratives production process. Therefore, it suggests that when associated to history teaching, education for citizenship establishes certain historical agents as a submissive position in comparison to the universe identified with Western civilization predominantly white and Christian - reinforcing the Eurocentric reference in history textbooks.

Keywords: Textbook. Education for citizenship. History Teaching.

\section{L'INCONCILIABLE DANS LESAVIS D'APPEL À LA CONCURRENCE DU PNLD (PROGRAMME NATIONAL DU MANUEL DIDACTIQUE):$$
\text { L'EUROCENTRISME, LA CITOYENNETÉ }
$$ ETL'ENSEIGNEMENT D'HISTOIRE}

Résumé: L'étude approche l'analyse des significations attribuées aux catégories d'enseignement de l'eurocentrisme, de la citoyenneté et de l'histoire établies par les avis d'appel à la concurrence pour le processus d'enregistrement et d'évaluation des ouvrages didactiques et littéraires publiés dans le « Diário Oficial da união » [Journal officiel] par le ministère de l'Éducation (MEC), soumis au Programme National des Manuels Scolaires (PNLD) et destinés à l'enseignement des collèges, entre 1996 et 2018. Dans ces derniers, il existe des présupposés guidant le processus d'évaluation du PNLD et liés à la production écrite de récits littéraires didactiques. En ce sens, il est argumenté que la quête de la formation de la citoyenneté, associée à l'enseignement de

\footnotetext{
${ }^{1}$ Doutoranda do Programa de Pós-Graduação em História Social da Amazônia (UFPA). Mestre em História Social da Amazônia pelo Programa de Pós-Graduação em História Social da Amazônia (UFPA). Licenciada em História pela Universidade Federal do Pará. Integrante do Núcleo de Estudos e Pesquisas sobre Formação de Professores e Relações Étnico-Raciais da UFPA (GERA/UFPA), do Grupo de Pesquisa de História indígena e do indigenismo na Amazônia (HINDIA/UFPA), e do grupo Oficinas de História (UERJ).
} 
l'histoire, place certains agents historiques en position de soumission à l'univers identifié à la civilisation occidentale - majoritairement blanche et chrétienne - renforçant la matrice de référence eurocentrique dans les manuels scolaires d'histoire.

Mots clés: Manuel scolaire. Formation à la citoyenneté. Enseignement d'histoire.

\section{LO IRRECONCILIABLE EN LOS AVISOS DEL PNLD (PROGRAMA NACIONAL DE LIBROS DE TEXTO): EUROCENTRISMO, CIUDADANIA Y ENSEÑANZA DE LA HISTORIA}

Resumen: El estudio aborda el análisis de los significados atribuidos a las categorías del eurocentrismo, ciudadanía e enseñanza de la historia orientado por los avisos de convocatoria para el proceso de registro y evaluación de trabajos didácticos y literarios publicados en el Boletín Oficial de la Unión, por el Ministerio de Educación (MEC), presentado al Programa Nacional de Libros de Texto (PNLD) y destinado a los Años Finales de Educación Primaria, entre 1996 y 2018. En estos, hay supuestos que guían el proceso de evaluación de PNLD y están relacionados con la producción de narraciones literarias didácticas. En este sentido, se argumenta que la búsqueda de la formación de ciudadanía, asociada con la enseñanza de la historia, coloca a ciertos agentes históricos en posición de sumisión al universo identificado con la civilización occidental - predominantemente blanca y cristiana - reforzando la matriz de referencia eurocéntrica en los libros de texto de historia.

Palabras clave: Libro de Texto. Formación de ciudadanía. Enseñanza de la historia.

\section{Introdução}

[...] a Educação e o Ensino de História emergem como espaços de lutas, resistências, esperanças e perspectivas. Falar da pluralidade do ensinar e aprender (História) hoje é defender a democracia, a liberdade de expressão e as utopias políticas cidadãs e humanistas. (RIBEIRO, 2019)

Na apresentação do livro Fazer História: a importância de ler, interpretar e escrever em sala de aula, Renilson Rosa Ribeiro instiga sobre a importância do saber histórico escolar para o desenvolvimento de condutas sociais que consolidem valores democráticos e o exercício da cidadania. Disto, decorre que a referida disciplina tornase objeto de conflitos, "como um locus de contradições, de pluralismo de ideias, de provisoriedade explicativa e de dinâmica interpretativa acerca da experiência humana no tempo" (CAIMI, 2016, p. 87). Isto é, a história escolar suscita discussões a respeito do conhecimento que deve ser ensinado, assim como de quais agentes e grupos sociais devem ser representados na educação básica.

Neste sentido, o presente texto constrói-se na perspectiva do saber histórico escolar. Isto é, compreende que o saber ensinado na escola básica possui conformações e demandas próprias $^{2}$. A reflexão propõe uma análise dos sentidos atribuídos às categorias eurocentrismo, cidadania e ensino de história nos editais de convocação para

2 Sobre a discussão em torno da categoria saber ou conhecimento histórico escolar, conferir: MONTEIRO, 2003; BITTENCOURT, 2004.; SILVA, 2019. 
o processo de inscrição e avaliação de obras didáticas e literárias publicados no Diário Oficial da União, pelo Ministério da Educação (MEC), submetidos ao Programa Nacional do Livro Didático (PNLD) e destinados aos Anos Finais do Ensino Fundamental, entre 1996 e 2018.

Argumenta-se que os sentidos de cidadania presentes na referida documentação, a qual regula e orienta o processo de avaliação, bem como interfere na produção dos livros didáticos, podem engendrar narrativas didáticas paradoxais pois, historicamente, o ensino de história no Brasil possui referenciais eurocêntricos que inviabilizam o desenvolvimento de raciocínio histórico e, ao mesmo tempo, acentuam as contradições da trajetória histórica de formação da sociedade brasileira estigmatizadas pela exclusão e pela desigualdade social. Isto é, busca-se uma educação para cidadania baseada em noções de respeito à diversidade que geram narrativas de submissão de determinados agentes ao universo identificado com a civilização ocidental - branca, cristã e masculina - reforçando, então, a tradição eurocêntrica ao invés de subvertê-la. Assim, eurocentrismo, cidadania e ensino de história despontam como categorias irreconciliáveis para a história ensinada na educação básica.

O período em questão explica-se pela estrutura de funcionamento do PNLD. Desde a instauração do processo de avaliação, em 1996, o programa costumava operar em ciclos trienais. A partir do Edital 01/2018, designado para a edição do PNLD 2020, o ciclo passou a ter o funcionamento de quatro anos. Desse modo, a análise do artigo parte dos editais publicados para os Anos Finais do Ensino Fundamental, os quais correspondem aos seguintes anos: 1999, 2002, 2005, 2008, 2011, 2014, 2017 e 2020. Ressalte-se que o processo avaliativo tem início nos dois anos anteriores ao da indicação de ano do programa, ou seja, ao se tratar dos livros didáticos aprovados para o "PNLD 1999", o procedimento iniciou-se em 1997, e assim sucessivamente.

O aporte teórico-metodológico fundamenta-se nos conceitos de discurso, de Mikhail Bakhtin (2006), e representação, de Roger Chartier (2002). Considera-se, assim, os editais do PNLD como enunciados discursivos em diálogo com outros, a saber: a Constituição Federal de 1988, a Lei de Diretrizes e Bases da Educação Nacional e suas alterações, as Diretrizes e/ou Parâmetros Curriculares Nacionais. Nestes documentos, por sua vez, são representados alguns agentes a exemplo de mulheres, afrodescendentes e povos indígenas. Desta feita, dentro do que propõe o historiador Roger Chartier em A História Cultural: entre práticas e representações, entende-se que a documentação do PNLD, assim como a legislação a qual lhe é subjacente, pode tanto 
regular como interferir diretamente na criação das obras didáticas ao produzir uma “ortodoxia do texto" (CHARTIER, 2002, p. 123). Assim, produz determinadas representações sobre os agentes históricos nas narrativas didáticas.

O artigo divide-se em três seções: na primeira, pretende dar conta das relações estabelecidas entre eurocentrismo, cidadania e ensino de história no Brasil conforme abordado pelos especialistas do campo de estudos sobre o conhecimento histórico escolar, de maneira que as considerações possibilitem o encaminhamento da análise dos editais. A segunda seção trata, especificamente, dos sentidos atribuídos às categorias nos editais do Programa Nacional do Livro Didático publicados entre 1996 e 2018. A terceira e última seção apresenta as considerações finais.

\section{O irreconciliável}

O debate em torno da tradição eurocêntrica presente na história ensinada na educação básica no Brasil, é amplamente tratado pelos especialistas do campo. Aliás, não sendo exclusividade das discussões sobre o conhecimento histórico escolar, apresenta-se como pauta no que se refere ao ofício do historiador, bem como nas áreas de estudos que analisam aspectos da trajetória de formação da sociedade brasileira.

Neste sentido, seria inviável versar sobre noções de (irre)conciliação sem retomar José Honório Rodrigues e a sua definição da política de conciliação: uma "arte finória" que exclui o povo, feita pelas elites dominantes, a qual costuma "rejeitar os interesses do povo, encarnação da Pátria, em cujo nome ela foi projetada e constituída" (RODRIGUES, 1982, p. 121). Assim, da necessidade de consolidar o Estado Nacional Brasileiro, resultou a criação do Colégio Pedro II e do Instituto Histórico e Geográfico Brasileiro, no século XIX. Segundo Katia Abud, ambas as instituições buscavam situar a recém-criada nação dentro da "civilização ocidental cristã", de maneira que este objetivo exigia o estabelecimento da relação direta do Brasil com o continente europeu, nas produções do IHGB e nos programas de ensino do Colégio Pedro II (ABUD, 2007, p. 108-109).

Em 1981, José Honório Rodrigues, na obra Filosofia e História, indicou uma determinada peculiaridade na conformação do que se entende por História do Brasil. De acordo com o referido historiador, a História do Brasil nada mais é do que a "história do que tem se passado na área da elite: superestrutural, ela é, politicamente, uma soma de arbítrio, terror, sítios, intervenções, conspirações, alienações, militarismo e pessoalmente o reino da mediocridade, e da exibição paranóica, com raros estadistas" 
(RODRIGUES, 1981, p. 13). Isto é, sem mencionar diretamente a matriz eurocêntrica, José Honório caracteriza a constituição da nossa história mais inclinada para uma determinada visão, a qual pode ser caracterizada como excludente.

Sobre a ideia de exclusão, Carlos Lessa (2008, p. 238) a relacionou com a trajetória de formação da sociedade brasileira e sua nacionalidade no século XIX afirmando que: "o traço específico é não tratar do povo". Sidney Chalhoub e Fernando Teixeira da Silva, no mesmo sentido, publicaram estudo abordando a questão por outra dimensão - a produção historiográfica brasileira - ou seja, o conhecimento produzido sobre a formação do Brasil moldou-se em torno da designação do Estado como o principal agente histórico gerando, assim, um "paradigma da ausência" (CHALHOUB e SILVA, 2009, p. 15). Em outras palavras, os demais agentes históricos não identificados com o Estado seriam considerados coadjuvantes da narrativa de formação da sociedade brasileira.

Não se pretende, com isso, desenvolver reflexão pautada pelo ídolo das origens, como alertado por Marc Bloch (2001, p. 56). Isto é, como se o ensino de história do Colégio Pedro II fosse exatamente o mesmo nos anos subseqüentes, ou ainda, se apenas a identificação da pauta eurocêntrica no contexto de criação da história do Brasil, acadêmica e ensinada, fosse o suficiente para a compreensão dos conflitos e demandas dessa disciplina escolar no tempo presente. Ocorre que, apesar das transformações ocorridas na história ensinada, no Brasil, o viés eurocêntrico persiste sendo apontado, pela literatura especializada sobre ensino de história, como uma questão de relevante influência nos programas curriculares e, principalmente, nos livros didáticos. À guisa de exemplo, pode-se citar os trabalhos de Elza Nadai (1993), Sonia Regina Miranda e Tania Regina de Luca (2004), Marcel Alves Martins (2012), Cinthia Monteiro de Araujo (2014), Mauro Cezar Coelho (2017), Helenice Rocha e Mauro Cezar Coelho (2018), dentre outros.

A relevância do assunto reside, ainda, no que Wilma de Nazaré Baía Coelho e Mauro Cezar Coelho, indicam como um dos desafios do saber escolar no cumprimento de leis como a 10.639 promulgada em 2003:

Ao propor a inclusão da História da África e da Cultura Afro-Brasileira, a política educacional encaminha uma revisão do protagonismo europeu e o abandono do princípio segundo o qual a nossa História é pautada pelos processos promovidos pelo Velho Mundo. (COELHO e COELHO, 2014, p. 99) 
Diante disto, os referidos autores ressaltam a necessidade de o currículo escolar encaminhar narrativas distintas e redimensionadas, ao invés de se restringir à inclusão de novos conteúdos. Isto é o que sugere, também, Mônica Lima (2017, p. 219), ao enfatizar a importância dos livros didáticos promoverem outras perspectivas nas narrativas, no que se refere ao tratamento da história da África e afro-brasileira, muito além de somente "inserir conteúdos" ou "substituir personagens de destaque".

Eis aí, portanto, uma das dimensões do que parece ser irreconciliável no ensino de história. A tradição de referencial eurocêntrico é incompatível com a trajetória histórica de formação da sociedade brasileira e da constituição da história ensinada no país. O viés eurocêntrico privilegia uma história de identificação com o universo europeu, ocidental, cristão, branco. Ou seja, distinta da composição de desigualdade socioeconômica, além da diversidade étnico-racial e cultural do Brasil. Importa frisar, neste ponto, que esta característica predominante no ensino de história não se conformou por conta do mero acaso. Antes, desenvolveu-se devido à uma função conformada para a história escolar ao longo do tempo: a formação para cidadania.

Segundo Katia Abud (2007, p. 110), embora uma série de reformas curriculares tenham gerado mudanças nos programas educacionais, formar cidadãos "unidos pelos laços da identidade nacional" continua sendo um preceito associado ao ensino de história. Assim, inicialmente, poderia ser questionado, neste texto, se ao invés de irreconciliável, as categorias eurocentrismo e cidadania não estariam, na verdade, bastante alinhadas, pois como debatido por José Honório Rodrigues, Carlos Lessa, Sidney Chalhoub e Fernando Teixeira da Silva, o processo de formação do Estado nacional - e da busca pelo cidadão nacional - engendrou a produção de narrativas historiográficas e escolares nas quais os agentes principais são aqueles identificados com a sociedade ocidental, branca, cristã. Logo, uma narrativa eurocêntrica era nada menos do que coerente com os objetivos das elites dominantes naquele contexto.

Porém, como mencionado previamente, a sociedade brasileira possui a diversidade como fator imprescindível na história de sua composição. E os agentes históricos, embora silenciados por discursos dominantes, tiveram (e continuam tendo) ações e intervenções nos eventos históricos. Neste sentido, Circe Bittencourt afirma que o modelo eurocêntrico predominou até a década de 1980. Com o alargamento da escolarização bem como do desenvolvimento das histórias social, cultural e marxista, escravos, colonos pobres, operários, enfim, os sujeitos considerados coadjuvantes da história passaram a ter maior visibilidade na história ensinada (BITTENCOURT, 2007, 
p. 43). Observe-se o caso dos povos indígenas. Desde a década de 1980, as representações sobre estes grupos tem sido objeto de reflexão no campo do ensino de história ${ }^{3}$, assim como as produções sobre história indígena e do indigenismo, nas universidades, passaram por reformulações que conformaram a chamada "nova história indígena", na qual "busca-se levar em conta a perspectiva dos próprios indígenas e colocar em cena as suas interpretações da história” (WITTMAN, 2015, p. 17).

Diz-se "nova", todavia, pela perspectiva do homem branco, tal como indicado por Manuela Carneiro da Cunha (1992, p. 18). Para os povos indígenas, sempre existiu uma história feita segundo as suas demandas ${ }^{4}$. Além dos referidos agentes terem pleno domínio sobre suas trajetórias históricas, a produção acadêmica que possui grupos indígenas como sujeitos históricos ressalta a participação dos mesmos na história do Brasil $^{5}$. Participação esta que ultrapassa a pretensão da política de conciliação da formação do Estado nacional - a identificação com as elites, ou mesmo com o universo ocidental. Importa ressaltar, ainda neste ponto, a definição de Mauro Cezar Coelho e Helenice Rocha sobre o protagonismo indígena no ensino de história. Para estes historiadores, trata-se de entender as ações dos indígenas "como resultado e resultante de escolhas, avaliações, contextos e situações que lhes são próprias, reconhecendo e incorporando a perspectiva indígena" (COELHO; ROCHA, 2018, p. 471). Para tanto, asseveram a importância de se redimensionar as abordagens e, principalmente, refutar a perspectiva eurocêntrica como predominante.

Foi no período da redemocratização, com o fortalecimento do Movimento Indígena e o reconhecimento das organizações sociais das etnias pela Constituição Federal de 1988, que uma série de inflexões ocorreram na educação básica, a exemplo da promulgação da Nova Lei de Diretrizes e Bases da Educação Nacional, em 1996. Nesse contexto, documentos como os Parâmetros Curriculares Nacionais e os editais do Programa Nacional do Livro Didático retomaram os princípios constitucionais com o objetivo de fortalecer o regime democrático. Esse aparato normativo passou a enfatizar

\footnotetext{
3 O estudo intitulado "A temática indígena e a diversidade cultural nos livros didáticos de história: uma análise dos livros recomendados pelo Programa Nacional do Livro Didático", de autoria de Izabel Gobbi, indica os trabalhos de Mauro Almeida e Norma Telles, ambos publicados em 1987, como prováveis pesquisas inaugurais da análise sobre a temática indígena nos livros didáticos de história. Cf. GOBBI, 2007, p. 36-42.

${ }^{4}$ Em palestra na Universidade Federal do Rio Grande do Sul, no ano 2015, Ailton Krenak demonstrou diferentes visões sobre o universo indígena a respeito da "herança colonial". Infere-se que as sociedades indígenas têm domínio sobre suas histórias independente do que a academia já produziu ou segue produzindo. Cf. KRENAK, 2015

${ }^{5}$ Sobre o assunto, conferir: ALMEIDA, 2013; MONTEIRO, 2003; CARVALHO JUNIOR, 2005.
} 
a respeito do necessário combate às discriminações e injustiças ocorridas ao longo da trajetória de formação da sociedade brasileira, conforme indica o seguinte excerto do volume de introdução aos Parâmetros Curriculares Nacionais, para o terceiro e o quarto ciclos do ensino fundamental, publicado em 1998:

Diante dessa conjuntura, há uma expectativa na sociedade brasileira para que a educação se posicione na linha de frente da luta contra as exclusões, contribuindo para a promoção e integração de todos os brasileiros, voltando-se à construção da cidadania, não como meta a ser atingida num futuro distante, mas como prática efetiva. A sociedade brasileira demanda uma educação de qualidade, que garanta as aprendizagens essenciais para a formação de cidadãos autônomos, críticos e participativos, capazes de atuar com competência, dignidade e responsabilidade na sociedade em que vivem e na qual esperam ver atendidas suas necessidades individuais, sociais, políticas e econômicas. (BRASIL, 1998, p. 21)

No excerto em evidência, a formação para cidadania é percebida como exigência prática e necessária diante das exclusões sociais presentes na sociedade brasileira. Busca-se, então, um cidadão autônomo, crítico, participativo, digno e responsável. Reside, então, aqui a segunda dimensão do irreconciliável no ensino de história: a cidadania. Por si, essa categoria já consiste em ser uma categoria irreconciliável em seus desdobramentos. Igualmente relacionada à criação do Estado nacional, a cidadania inicia sua conformação, no Brasil, fundamentada pelo estigma da exclusão.

O país delineou-se, como indica José Murilo de Carvalho (2015, p. 50-51), em torno da experiência escravocrata, da formação de grandes propriedades rurais, e um Estado mais inclinado a garantia de interesses privados dos setores dominantes no campo político e econômico. Ainda segundo o referido historiador, no período compreendido entre o fim do Império e o início da República, existiam diferentes concepções de cidadania, algumas de caráter político como o direito ao voto, outras tratavam de inspirações rousseaunianas defendendo que a cidadania se referia à concepção de quando o povo possuiria interesses comuns, ou mesmo as de inspiração positivista relacionadas aos direitos civis e sociais (CARVALHO, 2013, p. 64). Para José Murilo de Carvalho (2015, p. 16), pode-se entender como cidadania o pleno atendimento dos direitos civis, políticos e sociais, isto é, a garantia de vida, liberdade, igualdade, pensamento político diverso, acesso à educação, saúde, trabalho.

Ainda sobre os irreconciliáveis sentidos de cidadania, importa ressaltar a proposição de Wanderley Guilherme dos Santos. O autor relaciona as categorias de cidadania e ocupação, de acordo com a política econômico-social empreendida nos anos 
1930. Existe, desde então, no Brasil uma "cidadania regulada", pois ter uma profissão regulamentada é pré requisito para ser reconhecido como cidadão pelo Estado. Logo, sujeitos que não se enquadram no mercado formal de trabalho - trabalhadores da área rural, desempregados ou subempregados - não seriam percebidos como tal, já que "os direitos do cidadão restringem-se aos direitos do lugar que ocupa no processo produtivo" (SANTOS, 1987, p. 68). Desse modo, a promoção de cidadania implica na exclusão de determinados grupos sociais.

Em síntese, a sociedade brasileira é formada pela desigualdade étnico-racial, social, e, ainda, de gênero. Os sentidos de cidadania formulados são incompatíveis com a real composição do país. A respeito do tema, Lília Moritz Schwarcz afirma:

Outra pergunta: como é possível representar o país a partir da ideia de uma suposta coesão, partilhada por todos os cidadãos, quando ainda somos campeões no quesito desigualdade social, racial e de gênero, o que é comprovado por pesquisas que mostram a existência de práticas cotidianas de discriminação contra mulheres, indígenas, negros e negras, bem como contra pessoas LGBTTQ: Lésbicas, Gays, Bissexuais, Travestis, Transexuais e Queers? (SCHWARCZ, 2019, p. 23).

A historiadora percebe os diferentes níveis de desigualdade presentes na sociedade brasileira, que inviabilizam a aquisição de direitos fundamentais para o exercício da cidadania, principalmente em um país que pretende estar inserido em regime democrático. Esse descompasso, ou dentro do que propõe o presente texto, essa irreconciliação se desdobra como uma das demandas da história escolar e, mais precisamente, como questão pertinente ao universo de produção dos livros didáticos de história. Em 1985, a criação do Programa Nacional do Livro Didático consolidou esse suporte didático como uma política de Estado (CAIMI, 2017, p. 40). A dimensão legal do estabelecimento do PNLD como política estatal, de acordo com Jandson Soares e Margarida Dias (2019, p. 206-207), ocorreu com a promulgação do Decreto $n^{\circ} 7.084$, de janeiro de 2010. Essa medida desvinculou o programa de ações governamentais, além de ter formalizado os princípios orientadores dele. Tais princípios tem o objetivo de defender e assegurar o regime democrático por meio da educação básica.

A consolidação do estado democrático de direito demonstra-se enquanto fundamental no período posterior aos sucessivos governos militares. No que se refere ao desenvolvimento de cidadania, esta entra em pauta e passa a ser apresentada como a via pela qual a democracia pode ser consolidada. Isto é o que demonstra a documentação do Programa Nacional do Livro Didático, ou mais especificamente, a publicação dos 
editais de convocação para inscrição no processo de avaliação de obras didáticas, desde 1996. De acordo com Helenice Rocha, a importância desses editais e do processo avaliativo reside no fato de que as editoras precisam atender aos critérios estabelecidos pelo PNLD para serem adquiridas e distribuídas nas escolas da rede pública de ensino do país (ROCHA, 2017, p. 17).

Convém salientar que o PNLD foi o responsável por definir o "governo brasileiro, comprovadamente, desde 1996, como o maior comprador de livros no país" (FIGUEIREDO, 2017, p. 85). Neste sentido, as diretrizes do programa são fundamentais no que se refere à produção das obras didáticas e, no caso que interessa ao presente texto, da conformação dos conteúdos - substantivos e axiológicos - nos livros de história. Dada a sua relevância como política pública educacional e como ponto inicial da avaliação de livros didáticos feita por especialistas da área, os critérios prescritos nos editais do PNLD demandam perscrutação no sentido de se averiguar a maneira pela qual a tradição eurocêntrica, cidadania e ensino de história se entrecruzam, já que estas categorias parecem estar relacionadas de modo desalinhado entre si, além de incompatíveis com a sociedade brasileira, que tem a desigualdade e a exclusão como elementos da sua composição histórica.

\section{Os editais}

O edital da edição de 2020 do PNLD, publicado em 2018, introduz a convocação “com base no art. 208, VII, da Constituição Federal de 1988, na Lei no 9.394/1996 e no Decreto n 9.099/2017" (BRASílLIA, 2018). Tanto a Carta Magna como a Lei de Diretrizes e Bases da Educação Nacional são mencionadas em todos os editais do PNLD destinados ao processo de inscrição e avaliação de obras didáticas para os Anos Finais do Ensino Fundamental, isto é, desde 1999. A relevância de desvendar essa documentação é indicada por Alain Choppin e Kazumi Munakata. O primeiro adverte a respeito da importância de se compreender os livros didáticos dentro do "contexto legislativo e regulador" (CHOPPIN, 2004, p. 561) os quais lhes são equivalentes; o segundo, por seu turno, ressalta que a investigação sobre obras didáticas deve considerar "não apenas a elucidação de seus conteúdos, mas também dos procedimentos de sua produção, difusão, circulação, escolha e aquisição" (MUNAKATA, 2007, p. 138).

Neste sentido, cabe ressaltar que o foco desta análise é o universo de produção dos conteúdos das narrativas dos livros didático, ou seja, não se ocupa com as apropriações e usos das obras na escola básica. Assim, partindo das considerações dos 
dois autores previamente referenciados, verifica-se a necessidade de averiguar quais são as premissas, princípios ou diretrizes que regulam e orientam os editais do PNLD, pois estes consistem na etapa inicial de execução do programa, isto é, as etapas de inscrição e avaliação pedagógica das obras didáticas. Desse modo, pode-se verificar como a tradição eurocêntrica, cidadania e ensino de história se confrontam ou dialogam nessa documentação.

Em reflexão sobre a história do ensino de história no Brasil, Thais Nivia de Lima e Fonseca afirma:

No final dos anos 1970, com a crise do Regime Militar, o processo de redemocratização e o advento de novas possibilidades de se pensar a realidade brasileira, ficou mais clara a necessidade de se promoverem mudanças no ensino de História. Esse processo foi iniciado no princípio dos anos $1980 \mathrm{em}$ alguns estados brasileiros, resultando na elaboração de novos programas e novas propostas metodológicas para o ensino dessa disciplina nas escolas fundamental e média. (FONSECA, 2017, p. 63)

De acordo com a autora, ocorreram reformulações de programas e projetos no que se dizia respeito ao ensino de história, na conjuntura compreendida como final da ditadura civil-militar e o subsequente processo de redemocratização no qual o Brasil buscava constituir-se dentro dos moldes de um regime democrático. Importa frisar, ainda, que tais mudanças não foram exclusivas do campo do conhecimento histórico, acadêmico e escolar, antes podem (e devem) ser percebidas também como parte de um redimensionamento da educação básica como um todo.

Sobre as alterações de perspectivas no cenário educacional, expressas pela formação de uma nova Lei de Diretrizes e Bases da Educação Nacional, Eva Waisros Pereira e Zuleide Araújo Teixeira (2003, p. 89) indicam a relação feita nesta legislação, para a qual a educação básica passa a apresentar-se como um meio de assegurar a construção de democracia, de maneira que a cidadania plena poderia ser garantida ao transformar o indivíduo em sujeito da história por meio de uma "postura participante, crítica e libertadora".

Estas são premissas fundamentadas pela Constituição de 1988 e estão presentes no primeiro edital do PNLD destinado à avaliação de livros didáticos produzidos para os Anos Finais do Ensino Fundamental (ano 1999), conforme indica a coletânea 
Recomendações para uma política pública de livros didáticos. ${ }^{6}$ Assim, os critérios de avaliação - eliminatórios - comuns à todas as áreas do conhecimento, incluía:

Contribuição para a construção da cidadania. Em respeito à Constituição Brasileira e para contribuir efetivamente para a construção da ética necessária ao convívio social e à cidadania, o livro didático não poderá: veicular preconceitos de origem, cor, condição econdômica [sic] - social, etnia, gênero e qualquer outra forma de discriminação; fazer doutrinação religiosa, desrespeitando o caráter leigo do ensino público. Qualquer desrespeito a esses critérios é discriminatório e, portanto, socialmente nocivo. (BATISTA, 2001, p. 57)

De acordo com o excerto destacado, para ser aprovado no processo de avaliação do PNLD, um livro didático - de todas as disciplinas escolares presentes na educação básica - precisaria desenvolver uma cidadania coerente com certas expectativas diante da possibilidade de consolidação do regime democrático no Brasil. A cidadania é diretamente relacionada à certas posturas desejáveis diante das experiências sociais: rejeição de preconceitos e discriminação nas diferentes dimensões. Ações de preconceito e discriminação são consideradas "nocivas" e, portanto, implicariam na reprovação da obra.

Sendo documentos de natureza convocatória, os editais do PNLD são caracterizados por seções que tratam de informações gerais e específicas, a exemplo de período de inscrições, exigências de formato das obras didáticas, das etapas do processo de avaliação pedagógica e anexos contendo as especificações necessárias à padronização dos livros didáticos ofertados na educação básica. Dentre os anexos, estão os princípios e critérios de avaliação dessas obras didáticas, divididos em critérios comuns a todas as áreas do conhecimento, e, os critérios específicos de cada disciplina escolar. Diante do que pretende este artigo, a reflexão em curso enfatiza a análise nas seções de critérios específicos para a área de História.

Por meio dos editais é possível perceber a evolução do processo de avaliação, fato que é tratado pela própria documentação, pois os critérios são "aprimorados no decorrer do processo" (BRASÍLIA, 1999). Conforme indica Jandson Bernardo Soares (2017, p. 113), essa documentação ultrapassa a característica e funcionalidade essencialmente licitatória, pois interfere diretamente na produção dos livros didáticos levando em consideração não somente as mudanças ocorridas nas "ciências pedagógicas

\footnotetext{
${ }^{6}$ Segundo Holien Gonçalves Bezerra, a referida publicação é resultado de seminário ocorrido na cidade de São Paulo, em meados dos anos 2000, com representantes do Ministério da Educação, Coordenadores de Áreas do processo de avaliação, dentre outros especialistas. Apresenta as reformulações e modificações dos critérios de avaliação do PNLD. Cf. GOMES, 2013.
} 
e especializadas", mas também dialoga diretamente com as "necessidades da sociedade brasileira". Tendo em vista que o objetivo deste estudo é tratar das relações e sentidos atribuídos pela documentação às categorias de tradição eurocêntrica, formação para cidadania e ensino de história, estas são os referenciais para a reflexão sobre os critérios de avaliação de livros didáticos estabelecidos pelos editais do PNLD, do período entre $1999^{7}$ e 2020. Cabe ressaltar a especificidade da edição do PNLD/2020: este foi publicado após a homologação da Base Nacional Comum Curricular (BNCC); logo, possui distinções em relação aos processos anteriores. Neste sentido, o PNLD 2020 será apresentado em última instância, neste texto.

Em primeiro lugar, importa averiguar a concepção de história apresentada pelos editais. Isto é, qual é a função designada para o ensino de história na educação básica, de acordo com esta documentação. Para efeitos práticos, e com o objetivo de expor as similaridades, diferenças e avanços nos discursos da documentação, os anos serão apresentados em blocos de três - 2002/2005/2008 e 2011/2014/2017. Os quadros foram produzidos com base nas seções específicas para História nos editais. O quadro 1 a seguir destaca excertos dos três primeiros anos de avaliação pedagógica para os Anos Finais do Ensino Fundamental (2002, 2005 e 2008):

\footnotetext{
7 De acordo com a coletânea Recomendações para uma política pública de livros didáticos, os critérios de avaliação do PNLD de 1999 foram definidos em Seminário, realizado em Brasília, na Faculdade União Pioneira Integração Social - UPIS, ocorrido entre os dias 17 e 19 de junho de 1997. Não se tinham, portanto, critérios específicos para a área de História nessa edição do programa. $C f$. BATISTA, Antônio Augusto Gomes. Recomendações para uma política pública de livros didáticos. Brasília: Ministério da Educação, Secretaria de Educação Fundamental, 2001, p. 56.
} 
Quadro 1 - Concepção de História nos editais do PNLD 2002, 2005 e 2008.

\begin{tabular}{|c|c|c|}
\hline \multicolumn{3}{|c|}{ CONCEPÇÃO DE HISTÓRIA } \\
\hline 2002 & 2005 & 2008 \\
\hline $\begin{array}{l}\text { A História é um processo de compreensão } \\
\text { das diferentes e múltiplas possibilidades } \\
\text { existentes na sociedade, vistas da } \\
\text { perspectiva da experiência do presente. } \\
\text { Deve, portanto, possibilitar ao aluno uma } \\
\text { compreensão ativa da realidade, condição } \\
\text { para o desenvolvimento e a formação da } \\
\text { cidadania. (BRASÍLIA, 1999, p. 55). }\end{array}$ & $\begin{array}{l}\text { A História é um processo de compreensão } \\
\text { humana das diferentes e múltiplas } \\
\text { possibilidades existentes na sociedade, a } \\
\text { partir da experiência do presente. O livro de } \\
\text { História, portanto, deve possibilitar ao aluno } \\
\text { a compreensão ativa da realidade, que é } \\
\text { condição para o desenvolvimento e a } \\
\text { formação da cidadania. (BRASíLIA, 2002, } \\
\text { p. 50). }\end{array}$ & $\begin{array}{l}\text { Neste sentido, ensinar Historia hoje } \\
\text { pressupõe práticas educativas } \\
\text { adequadas às necessidades sociais e } \\
\text { culturais da sociedade brasileira, que } \\
\text { levem em consideração os interesses } \\
\text { e motivações dos alunos; exige, } \\
\text { ainda, que garanta aprendizagens } \\
\text { essenciais para a formação da } \\
\text { autonomia, da crítica e da } \\
\text { participação; deve, também, } \\
\text { colaborar para o despertar de } \\
\text { capacidades que auxiliem o aluno a } \\
\text { atuar na sociedade em que vive com } \\
\text { competência, dignidade } \\
\text { responsabilidade. (BRAŚ́LIA, 2005, } \\
\text { p. } 44 \text { ). } \\
206\end{array}$ \\
\hline
\end{tabular}

Fonte: Editais do Programa Nacional do Livro Didático de 1999 a 2005. Sistematização feita pela autora (2020). 
Conforme sugere o quadro comparativo, existem três principais objetivos relacionados à história como disciplina escolar na educação básica: possibilitar a compreensão do tempo presente, desenvolver um certo senso de participação na sociedade e formar para cidadania. De certo modo, essas três dimensões estão consubstanciadas umas nas outras, já que a noção de cidadania pressupõe alguma postura de intervenção, a qual não precisa ser, necessariamente, ações pragmáticas, podendo caracterizar-se por valores de respeito e tolerância, tal como prevê a legislação educacional. As premissas dos editais acima se desenvolvem, também, nos anos subseqüentes, de acordo com o quadro 2: 
Quadro 2 - Concepção de História nos editais do PNLD 2011, 2014 e 2017.

\begin{tabular}{|c|c|c|}
\hline \multicolumn{3}{|c|}{ CONCEPÇÃO DE HISTÓRIA } \\
\hline 2011 & 2014 & 2017 \\
\hline $\begin{array}{l}\text { [...] o pensar historicamente, que é o } \\
\text { objetivo central do ensino-aprendizagem } \\
\text { de História. Nesse sentido, é fundamental a } \\
\text { diferenciação entre a vivência desses } \\
\text { processos e a forma de produção de } \\
\text { conhecimento sobre eles, ou seja, a } \\
\text { compreensão do processo histórico e da } \\
\text { produção de conhecimento sobre o mesmo. } \\
\text { Da capacidade de discernir entre essas } \\
\text { duas dimensões da História derivará o } \\
\text { desenvolvimento de capacidades que } \\
\text { auxiliem o aluno a atuar na sociedade de } \\
\text { forma autônoma, crítica, participativa, } \\
\text { digna e responsável. (BRASÍLIA, 2008, p. } \\
\text { 46). }\end{array}$ & $\begin{array}{l}\text { Viabilizar o pensar historicamente é } \\
\text { o objetivo central do ensino- } \\
\text { aprendizagem de História e é por } \\
\text { meio desse processo que são } \\
\text { desenvolvidas as capacidades que } \\
\text { auxiliam o aluno a atuar na } \\
\text { sociedade de forma autônoma, } \\
\text { crítica, participativa, digna e } \\
\text { responsável. } \\
\text { Nesse sentido, é fundamental a } \\
\text { diferenciação entre a vivência desses } \\
\text { processos e a forma de produção de } \\
\text { conhecimento sobre eles, ou seja, a } \\
\text { compreensão do processo histórico e } \\
\text { da produção de conhecimento sobre } \\
\text { o mesmo. Da capacidade de discernir } \\
\text { entre essas duas dimensões da } \\
\text { História derivará o desenvolvimento } \\
\text { de capacidades que auxiliem o aluno } \\
\text { a atuar na sociedade de forma } \\
\text { autônoma, crítica, participativa, } \\
\text { digna e responsável. (BRASÍLIA, } \\
\text { 2011, p. 64). }\end{array}$ & $\begin{array}{l}\text { O Ensino de História numa perspectiva } \\
\text { contemporânea norteia-se por } \\
\text { pressupostos éticos, estéticos e culturais } \\
\text { comprometidos com a formação de } \\
\text { estudantes para a vivência social } \\
\text { marcada pela partilha, pela participação, } \\
\text { pelo respeito à diferença e pela } \\
\text { responsabilidade para com as gerações } \\
\text { futuras. (BRASÍLIA, 2011, p. 58). }\end{array}$ \\
\hline
\end{tabular}

Fonte: Editais do Programa Nacional do Livro Didático de 2008 a 2015. Sistematização feita pela autora (2020). 
Nota-se nos anos 2011 e 2014 uma menção que não estava presente nos editais anteriores, que é a ideia do "pensar historicamente". Esta é descrita como a habilidade de diferenciar entre a consecução dos eventos históricos e a produção de conhecimento feita a respeito dos mesmos. Na percepção destes editais, seria esta habilidade que permitiria a atuação na sociedade de maneira "autônoma, crítica, participativa, digna e responsável". Por seu turno, o documento de 2017 não retoma essa premissa e demonstra uma função para a história mais diretamente relacionada à preceitos éticos e condutas de "participação" e "respeito à diferença". Isto é, trata da cidadania encaminhada pela legislação, incorporada pelos editais e desejada para os livros didáticos, de todas as áreas do conhecimento, incluindo a história. O seguinte quadro 3, portanto, ilustra as noções de cidadania presentes nas seções de critérios de avaliação específicos da área de História, entre os anos de 2002 e 2008: 
Quadro 3 - Formação para cidadania nos editais de 2002, 2005 e 2008.

\begin{tabular}{|c|c|c|}
\hline \multicolumn{3}{|c|}{ Formação para cidadania } \\
\hline 2002 & 2005 & 2008 \\
\hline $\begin{array}{l}\text { Buscando o aprimoramento da } \\
\text { ética imprescindível ao convívio } \\
\text { social e à construção da } \\
\text { cidadania, no livro didático não se } \\
\text { deve expressar ou sugerir } \\
\text { preconceitos de qualquer natureza, } \\
\text { quais sejam os de origem, etnia, } \\
\text { gênero, religião, idade, nem } \\
\text { outras formas de discriminação, } \\
\text { quer no texto escrito, quer nas } \\
\text { ilustrações. (BRASÍLIA, 1999, p. } \\
\text { 58). }\end{array}$ & $\begin{array}{l}\text { Ele deve contribuir, portanto, para o } \\
\text { desenvolvimento da ética necessária ao } \\
\text { convívio social e à construção da } \\
\text { cidadania. Isso significa: } \\
\text { - não veicular, nos textos e nas } \\
\text { ilustrações, preconceitos que levem a } \\
\text { discriminações de qualquer tipo } \\
\text { (origem, etnia, gênero, religião, idade } \\
\text { ou quaisquer outras formas de } \\
\text { discriminação); } \\
\text { - não ser instrumento de propaganda ou } \\
\text { doutrinação religiosa; } \\
\text { - despertar para a historicidade das } \\
\text { experiências sociais, trabalhando } \\
\text { conceitos, habilidades e atitudes, na } \\
\text { construção da cidadania; } \\
\text { - estimular o convívio social e a } \\
\text { tolerância, abordando a diversidade da } \\
\text { experiência } \\
\text { humana, com respeito e interesse; } \\
\text { - desenvolver a autonomia de } \\
\text { pensamento, o raciocínio crítico, e a } \\
\text { capacidade de argumentar. (BRASÍLIA, } \\
\text { 2002, p. 54). }\end{array}$ & $\begin{array}{l}\text { Ele deve contribuir, portanto, para o } \\
\text { desenvolvimento da ética necessária ao convívio } \\
\text { social e à construção da cidadania. Isso significa: } \\
\text { - não veicular, nos textos e nas ilustrações, } \\
\text { preconceitos que levem a discriminações de qualquer } \\
\text { tipo (origem, etnia, gênero, religião, idade ou } \\
\text { quaisquer outras formas de discriminação); } \\
\text { - não ser instrumento de propaganda ou doutrinação } \\
\text { religiosa ou político-partidaria; } \\
\text { - não ser instrumento de propaganda mercadológica; } \\
\text { - despertar para a historicidade das experiências } \\
\text { sociais, trabalhando conceitos, habilidades e atitudes, } \\
\text { na construção da cidadania; } \\
\text { - estimular o convívio social e o reconhecimento da } \\
\text { diferença, abordando a diversidade da experiência } \\
\text { humana e a pluralidade social, com respeito e } \\
\text { interesse; } \\
\text { - desenvolver a autonomia de pensamento, o } \\
\text { raciocínio crítico e a capacidade de argumentar. } \\
\text { - estimular ações afirmativas em relação a questões } \\
\text { de gênero, orientação sexual e etnias. (BRASÍLIA, } \\
\text { 2005, p. 48). }\end{array}$ \\
\hline
\end{tabular}

Fonte: Editais do Programa Nacional do Livro Didático de 1999 a 2005. Sistematização feita pela autora (2020). 
É possível perceber a evolução do processo por meio da inclusão de tópicos nestes pontos dos textos da documentação, nos quais se demonstra o que significa formar para cidadania e, assim, quais são os aspectos que um livro didático de história precisa levar em consideração para ser aprovado pelo PNLD. Desde o edital de 2002 enfatiza-se a questão do combate a todo tipo de discriminação, e, com o passar dos anos, a cidadania estende-se para noções de respeito à diversidade, estímulo ao "convívio social", tolerância e reconhecimento da diferença. Assim, este padrão é seguido pelos anos seguintes, tal qual exposto pelo quadro 4, que foi construído a partir das seções dos editais nas quais os textos indicam quais requisitos deve possuir um livro didático para ser considerado aprovado: 
Quadro 4 - Formação para cidadania nos editais de 2011, 2014 e 2017.

\begin{tabular}{|c|c|c|}
\hline \multicolumn{3}{|c|}{ Formação para cidadania } \\
\hline 2011 & 2014 & 2017 \\
\hline $\begin{array}{l}\text { [...] desperta os alunos para a historicidade das } \\
\text { experiências sociais, trabalhando conceitos, } \\
\text { habilidades e atitudes, na construção da } \\
\text { cidadania. Estimula o convívio social e o } \\
\text { reconhecimento da diferença, abordando a } \\
\text { diversidade da experiência humana e a } \\
\text { pluralidade social, com respeito e interesse. Na } \\
\text { área de História, esses preceitos éticos, contudo, } \\
\text { só têm sentido se tratados historicamente, visto } \\
\text { que, desistoricizados, podem se revestir, apenas, } \\
\text { de ensinamentos morais e cívicos que não } \\
\text { condizem com os objetivos do ensino nem com a } \\
\text { produção do conhecimento histórico; } \\
\text { (BRAŚ́LIA, 2008, p. 47). }\end{array}$ & $\begin{array}{l}\text { 6. desperta os alunos para a } \\
\text { historicidade das experiências } \\
\text { sociais, trabalhando conceitos, } \\
\text { habilidades e atitudes, na } \\
\text { construção da cidadania; } \\
\text { 7. estimula o convívio social e o } \\
\text { reconhecimento da diferença, } \\
\text { abordando a diversidade da } \\
\text { experiência humana e a pluralidade } \\
\text { social, com respeito e interesse; } \\
\text { 8. trabalha os preceitos éticos de } \\
\text { forma contextualizada, visto que, } \\
\text { desistoricizados, podem resultar em } \\
\text { trechos, capítulos ou partes } \\
\text { dissociados da proposta geral da } \\
\text { coleção, se transformando, apenas, } \\
\text { em ensinamentos morais e cívicos } \\
\text { não condizentes, seja com os } \\
\text { objetivos do ensino, seja com a } \\
\text { produção do conhecimento } \\
\text { histórico; (BRASÍLIA, 2011, p. } \\
\text { 65). }\end{array}$ & $\begin{array}{l}\text { 6. situações de abordagem da historicidade } \\
\text { das experiências sociais, com vista à } \\
\text { construção da cidadania e das formas de } \\
\text { participação no mundo contemporâneo; } \\
\text { 8. estímulo ao convívio social e para o } \\
\text { reconhecimento da diferença, abordando a } \\
\text { diversidade da experiência histórica e a } \\
\text { pluralidade social, com respeito e interesse; } \\
\text { 16. isenção de estereótipos, caricaturas e/ou } \\
\text { simplificações explicativas } \\
\text { comprometam a noção de sujeito histórico } \\
\text { e/ou induzam à formação de preconceitos } \\
\text { de quaisquer natureza; (BRASÍlLIA, 2015, } \\
\text { p. 58-59). }\end{array}$ \\
\hline
\end{tabular}

Fonte: Editais do Programa Nacional do Livro Didático de 2008 a 2015. Sistematização feita pela autora (2020). 
Como demonstrado pelo quadro 4, o compromisso da história com a formação para cidadania trata, fundamentalmente, de desenvolver conceitos e aprendizagens históricas no intuito de estimular o "convívio social", o "reconhecimento da diferença", "respeito e interesse" para com a "diversidade da experiência humana e a pluralidade social”. Assim, em comparação com os demais editais, é possível notar a evolução do processo de avaliação e a incorporação de itens, no entanto, as bases do sentido de cidadania desenvolvida é, substancialmente, a mesma, já que esta documentação possui como referência, também, a Constituição Federal de 1988 e a Lei de Diretrizes e Bases da Educação Nacional de 1996. Estes dois referenciais, por meio da educação básica, exigem e buscam a garantia, justamente, da cidadania que respeita a liberdade, a tolerância, a pluralidade de ideias, a diversidade étnico-racial, dentre outros preceitos. ${ }^{8}$

Cabe ressaltar, neste ponto, uma peculiaridade dessa documentação: não se menciona, em nenhum dos editais, a tradição de referencial eurocêntrico, de maneira direta. $\mathrm{O}$ que se tem é a crítica a uma narrativa histórica que privilegie a apresentação de heróis, datas e fatos (BRASÍLIA, 1999, p. 57; BRASÍLIA, 2002, p. 55; BRASÍLIA, 2005, p. 49; BRASÍLIA, 2008, p. 45; BRASÍLIA, 2011, p. 64). Essa é uma questão que chama atenção, pois nos Guias de Livros Didáticos, etapa seguinte do processo de avaliação, no qual são expostos os pareceres dos especialistas sobre as coleções didáticas, a tradição eurocêntrica é colocada em pauta como discussão nas resenhas das obras. (BRASIL, 2001, p. 467; BRASIL, 2004, p.18; BRASIL, 2007, p. 98; BRASIL, 2010, p. 32; BRASIL, 2013, p. 66). Tomando este ponto como fio condutor, pode-se adentrar na análise do edital do PNLD de convocação para obras inscritas no processo de avaliação do quadriênio 2020-2024.

Como já mencionado acima, neste texto, o edital de 2020 é diferente dos anteriores. Neste, não há a definição dos critérios de avaliação específicos por áreas do conhecimento. O edital direciona os critérios para a Base Nacional Comum Curricular, afirmando que serão "excluídas as obras que não contribuírem adequadamente para o desenvolvimento de todas as competências gerais competências específicas das áreas de conhecimento, constantes na BNCC” (BRASÍLIA, 2018, p. 42). Neste sentido, a edição de 2020 do PNLD, tomando a BNCC como referencial direto, constitui-se na primeira vez em que ocorre certa problematização da narrativa de trajetória histórica de

\footnotetext{
${ }^{8}$ Cf. BRASIL. Lei no 9.934, de 20 de dezembro de 1996. Estabelece a lei de diretrizes e bases da educação nacional. Disponível em: https://www.planalto.gov.br/ccivil_03/Leis/L9394.htm. Acesso em 17 abril. 2020.
} 
constituição da sociedade brasileira pautada por um viés eurocêntrico. De acordo com o referido currículo nacional, as estereotipias construídas sobre a história da África e das culturas afro-brasileira e indígena se dão por conta da "produção de uma história brasileira marcada pela imagem de nação constituída nos moldes da colonização europeia" (BRASIL, 2017, p. 401).

Sobre a concepção de história, esta é indicada como a disciplina que estimula "autonomia de pensamento" e o reconhecimento de que "os indivíduos agem de acordo com a época e o lugar nos quais vivem"; logo, compreender a diversidade como eixo condutor da sociedade é fundamental para o desenvolvimento de "pensamento crítico, autonomia e formação para cidadania” (BRASIL, 2017, p. 400). Dentre as competências específicas de história para o ensino fundamental, estão listadas aquelas que podem promover condutas de "empatia”, "resolução de conflitos”, “cooperação”, "respeito", “democráticos", "inclusivos", "sustentáveis", "solidários”, etc. (BRASIL, 2017, p.402). Assim, a formação para cidadania continua seguindo as diretrizes percebidas tanto no aparato legal da educação básica como na documentação do PNLD desde a década de 1990.

\section{Considerações Finais}

Não se questiona a validade dos preceitos de cidadania apontados pela documentação. Ocorre que estes são incompatíveis com a tradição de referencial eurocêntrico que desconsidera a desigualdade e exclusão constitutivas da formação da sociedade brasileira. Embora o objetivo seja promover uma sociedade mais justa e igualitária, o efeito nas narrativas didáticas ocorre de maneira contraditória. Eis, então, a pertinência de se produzir análise sobre o assunto dentro do campo do ensino de história, uma vez que o saber histórico, no Brasil, segundo Erinaldo Cavalcanti (2008, p. 253), encontra-se "encastelado" dentro das universidades, onde a história ensinada é pouca enfatizada enquanto objeto de reflexão, apesar de ser "o espaço de atuação de todo professor". Isto é, o saber histórico escolar possui complexidades próprias, específicas e particulares, que transcendem, por exemplo, a comparação entre a história narrada pelo livro didático e a produção historiográfica. De acordo com Jandson Soares (2017, p. 110), a funcionalidade distinta da história no livro didático "torna o conhecimento histórico do livro didático diferente e, por sua vez, leva os sujeitos que habita o espaço escolar a disputarem e intervirem em seu formato". A diversidade nos 
livros didáticos, portanto, precisa transcender a condição de passividade para da conta das demandas da sociedade civil.

Para "conciliar" ou, como instigado por Erinaldo Cavalcanti, "desencastelar" a história, os livros didáticos precisam tratar os sujeitos históricos em nível equivalente de protagonismo, combatendo o eurocentrismo, e desenvolvendo lições de respeito e tolerância por meio das ações dos agentes que compõem a diversidade social e étnicoracial do país, ultrapassando o estatuto de informação, tal como verificado por Wilma de Nazaré Baía Coelho e Mauro Coelho (2012, p. 150), em estudo sobre o impacto da legislação para a educação das relações étnico-raciais nas escolas da região Norte. Em outras palavras, não basta apresentar um Brasil marcado pela desigualdade e pela diversidade no intuito de promover respeito e tolerância, é necessário redimensionar a perspectiva da sua trajetória histórica.

Em estudo sobre o assunto, Mauro Cezar Coelho e Taissa Bichara (2017) demonstraram que o Índio brasileiro cumpre, na história narrada pelos livros didáticos, uma função de formar para cidadania, que inviabiliza ações de protagonismo nos eventos históricos, pois apresenta-se como um dos agentes responsáveis pelo desenvolvimento de noções de diversidade, respeito e tolerância. Ainda que esteja presente e promova resistência diante do universo europeu em determinados pontos das narrativas, o destino dos povos indígenas destina-se ao desaparecimento, seja por meio de fugas, fracassos em guerras ou integração à fé cristã. Assim, ao promover condutas de cidadania, pautadas pelas premissas demonstradas no presente estudo, o Índio cumpriria determinada funcionalidade pedagógica, retirando-se da história do Brasil, e ressurgindo ocasionalmente. Neste sentido, sujeitos históricos como os povos indígenas apresentam-se nos livros didáticos diretamente relacionados às orientações do aparato legal e normativo que regula a educação básica, as quais definem o lugar do Índio na condição de personagem representativo da diversidade, que deve ser respeitado por conta disto. Não se pontua tal premissa como equivocada, no entanto, sua operacionalização nos livros didáticos produz o efeito contrário: o mundo europeu como protagonista e os povos indígenas em condição de dominação e assimilação.

Formar para cidadania implica, dentre uma série de questões, que agentes historicamente excluídos não representem de maneira passiva as lições de respeito e tolerância pela via do reconhecimento dos conflitos, desigualdades e exclusões nos eventos históricos narrados pelos livros didáticos. É necessária a crítica ao modelo eurocentrado e o desenvolvimento de múltiplos protagonismos. Nota-se, então a 
complexidade em torno da história como disciplina acadêmica e escolar. Este é um dos grandes desafios da história ensinada, pois a irreconciliação faz parte da trajetória histórica de formação da sociedade brasileira, da produção historiográfica e da história escolar. Assim, a formação de cidadania exige mais do que a ênfase nas condutas de respeito e tolerância, pois a diversidade que compõe a sociedade brasileira não se coloca diante dos acontecimentos passados e presentes de maneira passiva, antes luta, resiste e interfere diretamente na história do Brasil, construindo sentidos de cidadanias plurais.

\section{Referências}

\section{Fontes}

BRASIL. Secretaria de Educação Fundamental. Parâmetros curriculares nacionais: terceiro e quarto ciclos do ensino fundamental: introdução aos parâmetros curriculares nacionais / Secretaria de Educação Fundamental. - Brasília: MEC/SEF, 1998.

BRASÍLIA. Fundo Nacional de Desenvolvimento da Educação (FNDE). Edital de convocação para inscrição no processo de avaliação e seleção de livros didáticos a serem incluídos no "guia de livros didáticos de $5^{\mathrm{a}}$ a $8^{\mathrm{a}}$ séries" do PNLD/2002. Diário Oficial da União: Brasília, DF. [1999].

BRASÍLIA. Fundo Nacional de Desenvolvimento da Educação (FNDE). Edital de convocação para inscrição no processo de avaliação e seleção de obras didáticas a serem incluídas no guia de livros didáticos de $5^{\mathrm{a}}$ a $8^{\mathrm{a}}$ séries do PNLD/2005. Diário Oficial da União: Brasília, DF. 21/jun/2002.

BRASÍLIA. Fundo Nacional de Desenvolvimento da Educação (FNDE). Edital de convocação para inscrição no processo de avaliação e seleção de obras didáticas a serem incluídas no guia de livros didáticos para os anos finais do ensino fundamental PNLD/2008. Diário Oficial da União: Brasília, DF. 29/dez/2005.

BRASÍlLIA. Fundo Nacional de Desenvolvimento da Educação (FNDE). Edital de convocação para inscrição no processo de avaliação e seleção de coleções didáticas para o programa nacional do livro didático - PNLD 2011. Diário Oficial da União: Brasília, DF. [2008].

BRASÍLIA. Fundo Nacional de Desenvolvimento da Educação (FNDE). Edital de convocação para o processo de inscrição e avaliação de coleções didáticas para o programa nacional do livro didático PNLD 2014. Diário Oficial da União: Brasília, DF. $7 /$ nov/2011

BRASÍLIA. Fundo Nacional de Desenvolvimento da Educação (FNDE). Edital de convocação para o processo de inscrição e avaliação de obras didáticas para o programa nacional do livro didático PNLD 2017. Diário Oficial da União: Brasília, DF. 30/jan/2015. 
BRASÍLIA. Fundo Nacional de Desenvolvimento da Educação (FNDE). Edital de convocação n ${ }^{\circ}$ 1/2018 - CGPLI PNLD 2020. Diário Oficial da União: seção 3, Brasília, DF, $\mathrm{n}^{\circ} 60$, p.31, 28/ mar/2018.

BRASIL. Ministério da Educação. Base Nacional Comum Curricular (BNCC). Educação é a Base. Brasília, MEC/CONSED/UNDIME, 2017.

BRASIL. Ministério da Educação (MEC). Secretaria de Educação Básica (SEB). Guia de livros didáticos: PNLD 2001. Brasília, 2001.

BRASIL. Ministério da Educação (MEC). Secretaria de Educação Básica (SEB). Guia de livros didáticos: PNLD 2004. Brasília, 2004.

BRASIL. Ministério da Educação (MEC). Secretaria de Educação Básica (SEB). Guia de livros didáticos: PNLD 2007. Brasília, 2007.

BRASIL. Ministério da Educação (MEC). Secretaria de Educação Básica (SEB). Guia de livros didáticos: PNLD 2010. Brasília, 2010.

BRASIL. Ministério da Educação (MEC). Secretaria de Educação Básica (SEB). Guia de livros didáticos: PNLD 2013. Brasília, 2013.

BATISTA, Antônio Augusto Gomes. Recomendações para uma política pública de livros didáticos. Brasília: Ministério da Educação, Secretaria de Educação Fundamental, 2001.

\section{Bibliografia}

ABUD, Katia Maria. A história nossa de cada dia: saber escolar e saber acadêmico na sala de aula. In: MONTEIRO, Ana Maria; GASPARELLO, Arlete Medeiros; MAGALHÃES, Marcelo de Souza (Orgs.). Ensino de história: sujeitos, saberes e práticas. Rio de Janeiro: Mauad X: FAPERJ, 2007.

ARAUJO, Cinthia Monteiro. Por outras histórias possíveis: construindo uma alternativa à tradição moderna. In: MONTEIRO, Ana Maria [et al.]. Pesquisa em ensino de história: entre desafios epistemológicos e apostas políticas. 1 ed. Rio de Janeiro: Mauad X, Faperj, 2014.

BAKHTIN, Mikhail. Marxismo e filosofia da linguagem: problemas fundamentais do método sociológico da linguagem. Trad. Michel Lahud Et Al. 12. ed. São Paulo: Hucitec, 2006.

BITTENCOURT, Circe. Identidade e ensino da história no Brasil. In: CARRETERO, Mario; ROSA, Alberto; GONZÁLEZ, Maria Fernanda (orgs.). Ensino da história e memória coletiva. Porto Alegre: Artmed, 2007.

BITTENCOURT, Circe. Os confrontos de uma disciplina escolar: da história sagrada à história profana. Revista Brasileira de História. São Paulo, v. 13, n. 25/26, p. 193-221, set./ago. 1993. 
BLOCH, Marc. Apologia da história ou o ofício de historiador. Rio de Janeiro: Jorge Zahar Ed., 2001.

CAIMI, Flávia. A História na Base Nacional Comum Curricular: pluralismo de ideias ou guerra de narrativas?. Revista do Lhiste, Porto Alegre, num.4, vol.3, jan/jun. 2016.

CAIMI, Flávia. O livro didático de história e suas imperfeições: repercussões do PNLD após 20 anos. In: ROCHA, Helenice; REZNIK, Luis; MAGALHÃES, Marcelo de Souza. Livros didáticos de história: entre políticas e narrativas. Rio de Janeiro: FGV Editora, 2017.

CARNEIRO, Manuela Carneiro da. Introdução a uma história indígena. In: (org.). História dos índios no Brasil. São Paulo: Companhia das Letras: Secretaria Municipal de Cultura: Fapesp, 1992.

CARVALHO, José Murilo de. Os bestializados: o Rio de Janeiro e a República que não foi. São Paulo: Companhia das Letras, 2013.

Cidadania no Brasil: o longo caminho. 19a ed. Rio de Janeiro: Civilização Brasileira, 2015.

CASSIANO, Célia Cristina de Figueiredo. Política e economia do mercado do livro didático no século XXI: globalização, tecnologia e capitalismo na educação básica nacional. In: ROCHA, Helenice; REZNIK, Luis; MAGALHÃES, Marcelo de Souza (orgs.). Livros didáticos de história: entre políticas e narrativas. Rio de Janeiro: FGV Editora, 2017.

CAVALCANTI, Erinaldo. A história encastelada e o ensino encurralado: reflexões sobre a formação docente dos professores de história. Educar em Revista, Curitiba, Brasil, v. 34, n. 72, p. 249-267, nov./dez. 2018.

CHALHOUB, Sidney; SILVA, Fernando Teixeira de. Sujeitos no imaginário acadêmico: escravos e trabalhadores na historiografia brasileira desde os anos 1980 . Cadernos Arquivo Edgar Leuenroth, v.14, n.26, 2009.

CHARTIER, Roger. A história cultural: entre práticas e representações. 2.ed. Tradução de Maria Manuela Galhardo. Algés, Portugal: Difel, 2002.

CHOPPIN, Alain. História dos livros e das edições didáticas: sobre o estado da arte. Educação e Pesquisa, São Paulo, v.30, n.3, p. 549-566, set./dez. 2004.

COELHO, Mauro Cezar. A história, o índio e o livro didático: apontamentos para uma reflexão sobre o saber histórico escolar. In: ROCHA, Helenice Aparecida Bastos; REZNIK, Luís; MAGALHÃES, Marcelo de Souza (org.). A história na escola: autores, livros e leituras. Rio de Janeiro: Ed. FGV, 2009.

COELHO, Wilma de Nazaré Bahia; COELHO, Mauro Cezar. Por linhas tortas - a educação para a diversidade e a questão étnico-racial em escolas da Região Norte: entre virtudes e vícios. Revista da ABPN. v. 4, n. 8. jul - out. 2012. 
COELHO, Mauro Cezar; BICHARA, Taissa. A história de um passado "injusto": povos indígenas, livro didático e formação para cidadania. História UNICAP, v. 4, p. 75-89, 2017.

; ROCHA, Helenice Aparecida Bastos. Paradoxos do protagonismo indígena na escrita escolar da História do Brasil. Tempo e Argumento, Florianópolis, v. 10, n. 25, p. 464 - 488, jul./set. 2018.

COELHO, Wilma de Nazaré Baía; COELHO, Mauro Cezar. "Jogando verde e colhendo maduro". Historiografia e saber histórico escolar no ensino da história e da cultura afrobrasileira. In: Entre virtudes e vícios: educação, sociabilidades, cor e ensino de história. São Paulo: Editora Livraria da Física, 2014.

COELHO, Mauro Cezar. Que enredo tem essa história? A colonização portuguesa na América nos livros didáticos de história. In: ROCHA, Helenice; REZNIK, Luis; MAGALHÃES, Marcelo de Souza (orgs.). Livros didáticos de história: entre políticas e narrativas. Rio de Janeiro: FGV Editora, 2017.

FONSECA, Thais Nivia de Lima e. História \& ensino de história. 4. ed. Belo Horizonte: Autêntica Editora, 2017.

GREVER, Maria; VLIES, Tina van der. Why national narratives are perpetuated: a literature review on new insights from history textbook research. London Review of Education. London, vol. 15, n. 2, p. 286-301, 2017.

LESSA, Carlos. Nação e nacionalismo a partir da experiência brasileira. Estudos Avançados. São Paulo, v. 22, n. 62, p. 237-256, 2008.

LIMA, Mônica. Negra é a raiz da liberdade. Narrativas sobre a abolição da escravidão no Brasil em livros didáticos de história. In: ROCHA, Helenice; REZNIK, Luis; MAGALHÃES, Marcelo de Souza (orgs.) Livros didáticos de história: entre políticas e narrativas. Rio de Janeiro: FGV Editora, 2017.

MARTINS, Marcel Alves. O eurocentrismo nos programas curriculares de História: 1942-2008. Dissertação (Mestrado em Educação). Pontifícia Universidade Católica de São Paulo. São Paulo, SP, 2012.

MIRANDA, Sonia Regina; LUCA, Tania Regina de. O livro didático de história hoje: um panorama a partir do PNLD. Revista Brasileira de História. São Paulo, v. 24, n. 48, p. 123-144. 2004.

MUNAKATA, Kazumi. O livro didático e o professor: entre a ortodoxia e a apropriação. In: MONTEIRO, Ana Maria; GASPARELLO, Arlette Medeiros; MAGALHÃES, Marcelo de Souza (orgs.). Ensino de história: sujeitos, saberes e práticas. Rio de Janeiro: Mauad X, FAPERJ, 2007.

NADAI, Elza. O ensino de história no Brasil: revisitando a história da disciplina nas últimas décadas do século XX. Revista brasileira de história. São Paulo, v. 3, n. 25/26, 1993. 
PEREIRA, Eva Waisros; TEIXEIRA, Zuleide Araújo. A educação básica redimensionada. In: BRZEZINSKI, Iria (org.). LDB INTERPRETADA: diversos olhares se entrecruzam. 8.ed. São Paulo: Cortez, 2003.

RIBEIRO, Renilson Rosa. Ensino de história, instituição escolar e saber-fazer docente. In: _. Fazer história: a importância de ler, interpretar e escrever em sala de aula. 1.ed. Curitiba: Appris, 2018.

ROCHA, Helenice. Livro didático de história em análise: a força da tradição e transformações possíveis. In: ROCHA, Helenice; REZNIK, Luis; MAGALHÃES, Marcelo de Souza (orgs.). Livros didáticos de história: entre políticas e narrativas. Rio de Janeiro: FGV Editora, 2017.

RODRIGUES, José Honório. Conciliação e reforma no Brasil: um desafio histórico cultural. Rio de Janeiro: Nova Fronteira, 1982.

Filosofia e História. Rio de Janeiro: Nova Fronteira, 1981.

SANTOS, Wanderley Guilherme dos. Cidadania e justiça: a política social na ordem brasileira. 2.ed. Rio de Janeiro: Campus, 1987.

SCHWARCZ, Lilia Moritz. Sobre o autoritarismo brasileiro. São Paulo: Companhia das Letras, 2019.

SOARES, Jandson Bernardo. Espaço escolar e livro didático de história no Brasil: a institucionalização de um modelo a partir do Programa Nacional do Livro Didático (1994 a 2014). Dissertação (Mestrado) - Universidade Federal do Rio Grande do Norte. 2017.

SOARES, Jandson; DIAS, Margarida. Programa Nacional do Livro Didático (PNLD). In: FERREIRA, Marieta de Moraes; OLIVEIRA, Margarida Dias de (orgs.). Dicionário de ensino de história. Rio de Janeiro: FGV Editora, 2019.

WITTMAN, Luiza Tombini (org.). Ensino (d)e história indígena. Belo Horizonte: Autêntica, 2015.

Artigo recebido em 30 de junho de 2020. Aprovado em 03 de novembro de 2020. 